\title{
Heavy Snowfall in Kanto and on the Pacific Ocean Side of Northern Japan Associated with Western Pacific Blocking
}

\author{
Akira Yamazaki ${ }^{1}$, Meiji Honda ${ }^{2}$, and Akira Kuwano-Yoshida ${ }^{1}$ \\ ${ }^{1}$ Application Laboratory, Japan Agency for Marine-Earth Science and Technology, Yokohama, Japan \\ ${ }^{2}$ Faculty of Science, Niigata University, Niigata, Japan
}

\begin{abstract}
The influence of large-scale atmospheric blocking over the northwestern Pacific on heavy snowfall events in the Kanto area and on the Pacific Ocean side of northern Japan (PNJ) within the time scale of $\sim 10$ days was examined through blocking case studies. The past 14 blocking cases over the Pacific, including the blocking during early- to mid-February 2014 that influenced a record-breaking snowfall over the Kanto area, were analyzed using a long-term reanalysis dataset and local meteorological observation station data. Results reveal that blocking over the Pacific causes large precipitation over the Kanto area and the PNJ by shifting cyclone (storm) tracks towards the east coast of Japan from their usual eastward course across the mid-Pacific via the south coast of Japan. Excessive passing of cyclones caused large precipitation in the Kanto area and snowfall in the PNJ. In the blocking cases with heavy snowfall events in the Kanto area, a strong cold-air inflow over Japan also existed in the lower troposphere originating from east Siberia, which initiated synoptic ground cold-air environments in the Kanto area.
\end{abstract}

(Citation: Yamazaki, A., M. Honda, and A. Kuwano-Yoshida, 2015: Heavy snowfall in Kanto and on the Pacific Ocean side of northern Japan associated with western Pacific blocking. SOLA, 11, 59-64, doi:10.2151/sola.2015-013.)

\section{Introduction}

Atmospheric blocking is a large-scale phenomenon in which a large anticyclone with a radius of $\sim 5000 \mathrm{~km}$ stagnates in the upper troposphere in mid-latitudes for a period of at least one week and disrupts the prevailing westerly circumpolar flow. Since blocking repeatedly disrupt usual circumpolar flow, they can trigger various weather extremes by affecting synoptic (several days and $\sim 1000 \mathrm{~km}$ scale) atmospheric conditions. Blocking in the Northern Hemisphere are the most frequent over the Atlantic and Pacific (e.g., Pelly and Hoskins 2003), and one occurred during early- to mid-February 2014 over the western Pacific just east of Japan.

Blocking exerts particular influence on tracks of synoptic cyclones (storm tracks). Accompanied by persistent meandering or splitting of disrupted westerlies, storm tracks are steered toward the direction of the westerlies (e.g., Green 1977). Thus, it was possible for the February 2014 blocking to regulate the paths of the two cyclones that hit the Kanto area (Fig. 1a) during 7-9 and 14-16 February 2014. Both cyclones dumped significant snow over the metropolitan area, around Tokyo, where snowfall events rarely occur even in winter. Therefore, we investigate whether similar events associated with past blocking occurred and how western Pacific blocking caused the February 2014 snowfall events from a large-scale viewpoint.

Corresponding author: Akira Yamazaki, Application Laboratory, Japan Agency for Marine-Earth Science and Technology, 3173-25 Showa-machi, Kanazawa-ku, Yokohama, Kanagawa 236-0001, Japan. E-mail: yzaki@ jamstec.go.jp. (C2015, the Meteorological Society of Japan.

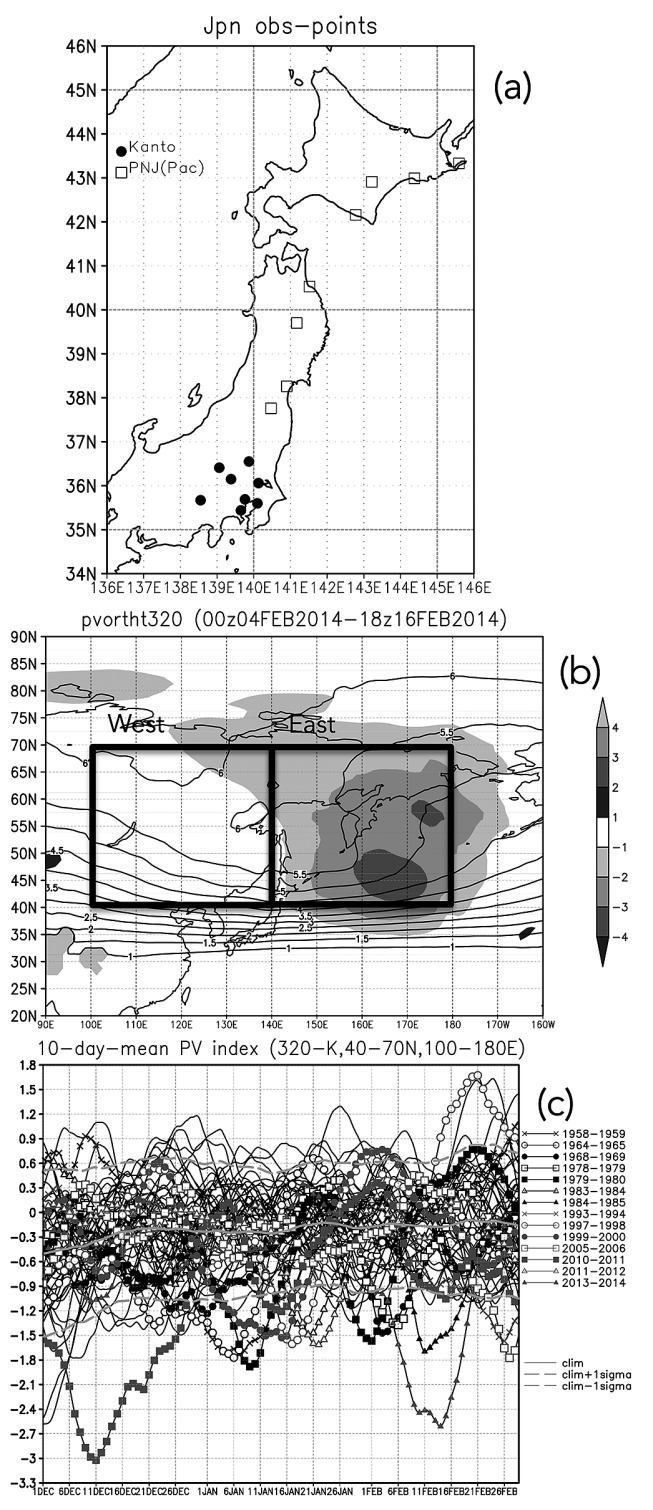

Fig. 1. (a) Geographical locations of the Kanto (dots) and Pacific Ocean side of northern Japan (PNJ, squares) areas. The dots and squares indicate the local observation points for the areas (for Table 2 and Fig. 3). The place names of the points for the Kanto and PNJ areas are denoted in Table 2. (b) Averaged PV anomalies (shades, $\left[10^{-6} \mathrm{~m}^{2} \mathrm{~K} \mathrm{~kg}^{-1} \mathrm{~s}^{-1}\right]$ ) and climatology (contours, $\left[10^{-6} \mathrm{~m}^{2} \mathrm{~K} \mathrm{~kg}^{-1} \mathrm{~s}^{-1}\right]$ ) at $320 \mathrm{~K}$ isentropic surface during 4-16 February 2014. The squares denoted as "West" and "East" in the figure indicate the frames of the western $\left(100^{\circ} \mathrm{E}-140^{\circ} \mathrm{E}, 40^{\circ} \mathrm{N}-70^{\circ} \mathrm{N}\right)$ and eastern $\left(140^{\circ} \mathrm{E}-180^{\circ} \mathrm{E}, 40^{\circ} \mathrm{N}-70^{\circ} \mathrm{N}\right)$ regions for calculating the blocking index $I_{D}$. (c) Time sequences of the blocking indices $I_{D}\left[10^{-6} \mathrm{~m}^{2} \mathrm{~K} \mathrm{~kg}^{-1} \mathrm{~s}^{-1}\right]$ for all the winters (1958-2014). The 14 lines with marks represent the time sequences of the winters including the selected blocking days, while the other thin black lines are those of the other winters. The thick grey line and the dashed lines are the climatology and the 1-standard deviations from the climatology, respectively. All the time sequences are 10-day running averages. 


\section{Composite study}

We extracted past western Pacific blocking similar to the February 2014 blocking and composited atmospheric conditions in the blocking. We used the long-term global reanalysis of the JRA-55 (6 hourly, $1.25 \times 1.25$ degrees; Kobayashi et al. 2015). The analysis period consisted of winters (December to February) from 1958 to 2014 (i.e., 57 winters). An anomaly of a particular variable for a given event was defined as its departure from the climatological-mean annual cycle value for the corresponding calendar day. The annual cycle (climatology) was calculated as the average field of the 57-year period.

Detection of blocking was conducted using Ertel's potential vorticity (PV) for the $320 \mathrm{~K}$ surface almost corresponding to the tropopause in mid-latitude winter. PV is advantageous for analyzing blocking (e.g., Yamazaki and Itoh 2013). Figure 1b shows the PV anomalies averaged over the 4-16 February 2014 blocking event. The blocking anticyclone, which is characterized by a strong negative PV anomaly, can be found over the northwestern Pacific, east of Japan. Based on the anomaly distribution, the index for detecting western Pacific blocking is defined as follows:

$$
I_{D} \equiv P_{E}-P_{W},
$$

where $P_{\mathrm{E}}$ and $P_{\mathrm{W}}$ are the area-averaged (raw-value) PV within the frames of $140^{\circ} \mathrm{E}-180^{\circ} \mathrm{E}, 40^{\circ} \mathrm{N}-70^{\circ} \mathrm{N}$ and $100^{\circ} \mathrm{E}-140^{\circ} \mathrm{E}, 40^{\circ} \mathrm{N}-$ $70^{\circ} \mathrm{N}$, respectively. A smaller $I_{D}$ indicates a stronger negative PV anomaly within the "East" frame (Fig. 1b), since $I_{D}$ amplitudes for prominent blocking were almost completely attributable to $P_{E}$, as later shown in Fig. 2a. The blocking period was defined to the date on which the index $I_{D}$ became obviously lower than the climatological values, during 11 December to the end of February. The difference in the blocking index for the east-west direction was to avoid detecting the blocking over Japan or west of Japan and the seasonal PV distribution march during winter caused by the shift in the north-south distribution. Hereafter, all climatology and anomaly values are denoted as 10-day running-means because the days correspond to the typical time-scale of blocking.

Figure 1c shows the time sequences of $I_{D}$ during winters of the 57 years. The 14 strongest blocking during 14 winters in which $I_{D}$ took smaller values than 1.5 standard deviations from its climatology were then selected as blocking cases (Table 1). The minimum $I_{D}$ dates for these 14 blocking cases were denoted as the blocked days, and the 10-day running mean was applied to these days.

\subsection{Large-scale feature related to the western Pacific blocking}

Large-scale circulation fields for blocking were characterized by compositing the 14 blocking cases. Figures $2 a$, b, c show geo-

Table 1. Blocking cases (case names) and their blocked days for the selected 14 cases by using the blocking indices $I_{D}$. The blocked days are the minimum $I_{D}$ dates for the 14 winters (from 11 December to the end of February) in which $I_{D}$ takes smaller values than 1.5 standard deviations from its climatology.

\begin{tabular}{cc}
\hline Case \# & Blocked days \\
\hline 195901 & 7 Jan 1959 \\
196501 & 6 Jan 1965 \\
196902 & 3 Feb 1969 \\
197902 & 5 Feb 1979 \\
198001 & 9 Jan 1980 \\
198401 & 20 Jan 1984 \\
198502 & 11 Feb 1985 \\
199402 & 26 Feb 1994 \\
199801 & 17 Jan 1998 \\
200001 & 15 Jan 2000 \\
200602 & 27 Feb 2006 \\
201012 & 11 Dec 2010 \\
201201 & 21 Jan 2012 \\
201402 & 13 Feb 2014 \\
\hline
\end{tabular}
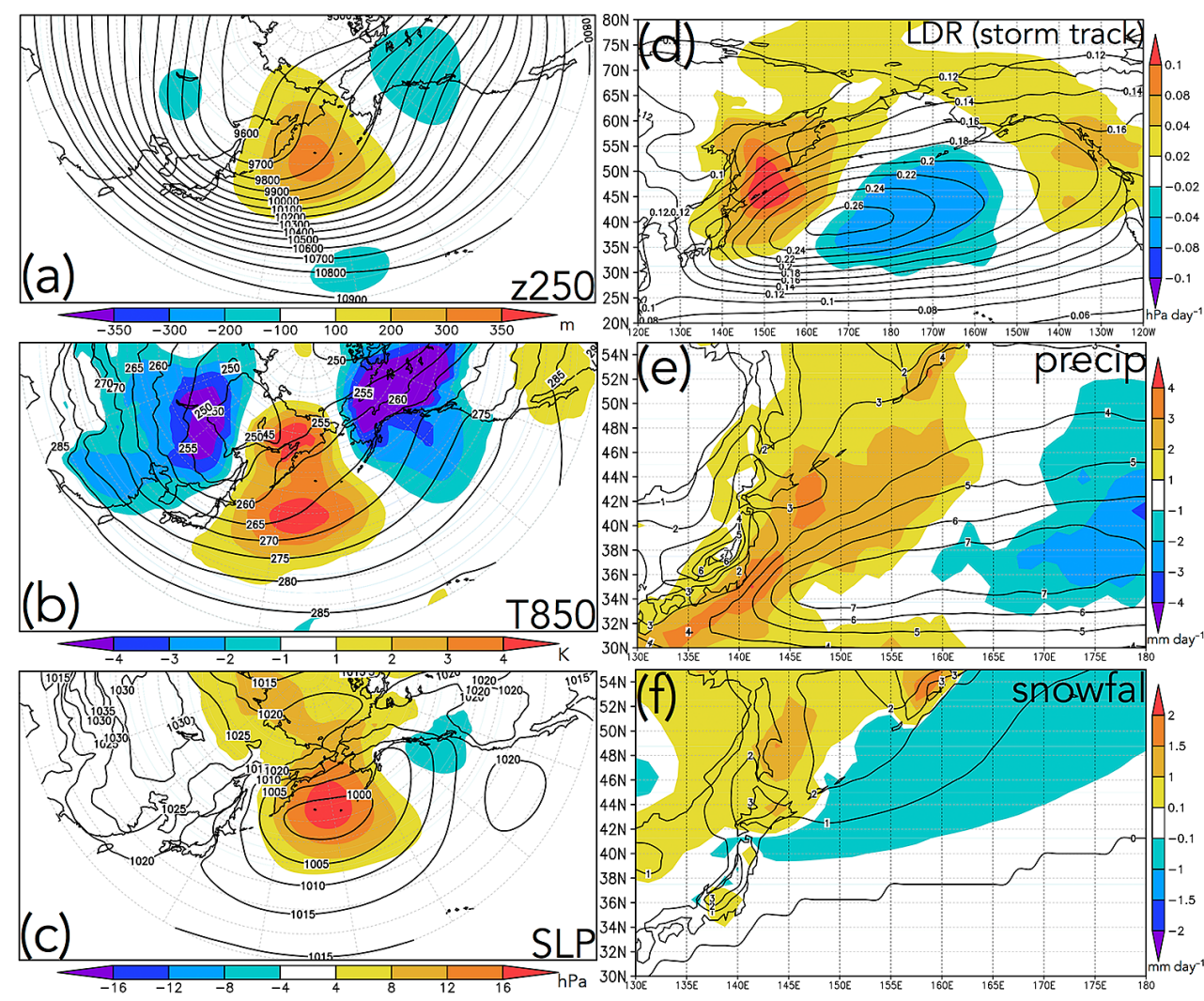

Fig. 2. Composite maps for the 14 blocking. The anomalies (shades) and the climatology (contours) of (a) geopotential height [m] at $250 \mathrm{hPa}$, (b) temperature $[\mathrm{K}]$ at $850 \mathrm{hPa}$, (c) sea-level pressure $[\mathrm{hPa}]$, (d) the storm tracks [hPa day $\left.{ }^{-1}\right]$ defined by the local deepening rate $\sigma_{\mathrm{LDR}}$, and $6 \mathrm{~h}$ forecast (e) precipitation $\left[\mathrm{mm}\right.$ day $\left.^{-1}\right]$, and (f) snowfall $\left[\mathrm{mm} \mathrm{day}^{-1}\right]$ fields are shown. 
potential height anomalies at $250 \mathrm{hPa}$, temperature anomalies at $850 \mathrm{hPa}$, and sea-level pressure anomalies. Blocking anticyclones correspond to the apparent large-amplitude anticyclonic anomalies prevailing from the upper to lower troposphere just east of Japan, which overlap with low-level warm anomalies. Although the temperature anomaly field also shows intensification of lowertropospheric cold air over Siberia, remarkable anomalies are not found around Japan.

The storm-track anomalies are shown in Fig. 2d. The tracks were quantified by the local deepening rate $\left(\sigma_{\mathrm{LDR}}\right)$ defined by Kuwano-Yoshida (2014) as follows:

$$
\begin{aligned}
\sigma_{\mathrm{LDR}} & \equiv \max \left(-p_{t}, 0\right), \\
p_{t} & =\frac{p_{\mathrm{MSL}}(t+12 \mathrm{~h})-p_{\mathrm{MSL}}(t-12 \mathrm{~h})}{24 \mathrm{~h}}\left|\frac{\sin 60^{\circ}}{\sin \varphi}\right|,
\end{aligned}
$$

where $p_{t}$ is the pressure tendency at time $t, p_{\mathrm{MSL}}$ is sea-level pressure $^{1}, \varphi$ is latitudes [deg], and $\mathrm{h}$ is hours. A larger deepening rate indicates more passing cyclones ${ }^{2}$.

This figure clearly shows that the courses of the cyclones (storm track) that formed south of Japan shifted northeastward from their usual eastward paths. The anomalies of $6 \mathrm{~h}$ forecast precipitation and snowfall in JRA-55 associated with the blocking are shown in Figs. 2e, f. Precipitation was found to increase along the storm track associated with the blocking; an increased number of cyclones passing near the Kanto area and the Pacific Ocean side of northern Japan (PNJ) resulted in an anomalous increase of precipitation on a 10-day time scale. Hereafter, we refer to this precipitation that occurs within this time scale as "unusual" precipitation. Such a precipitation distribution change is consistent with the case study conducted by Green (1977) on the blocking that occurred in July 1976 near the United Kingdom. Similarly, Ueno (1993) reported that some teleconnection patterns (i.e., large-scale atmospheric phenomena other than blocking) influenced precipitation distribution over the Pacific region of Japan in winter via shifting storm tracks. This also supports our results showing that the precipitation distribution mainly results from changes in storm tracks. In contrast, snowfall distribution did not show a clear increase in the global reanalysis compared to precipitation. However, since the results of Figs. 2e, $f$ are based on $6 \mathrm{~h}$ forecast values, they are less reliable than those obtained from local observation station data.

\subsection{Precipitation/snowfall variations in local observation data}

More robust results on the unusual precipitation/snowfall in the Kanto area and the PNJ influenced by blocking can be obtained by using local observation station data during blocking events. For the observation points, eight points in the Kanto area and eight points in the PNJ were selected (see Table 2). Every point's data in each area was summed up and averaged. The data used in this study were precipitation and snowfall amounts during one-third of a month (i.e., one decade). Thus, one winter included nine decades. A decade that included a blocked day was defined as a blocking decade, and the period including the blocking decade, the preceding and following decades (total 3 decades) was defined as a blocking period. For the definition of a blocking period, the persistence of strong blocking (more than 10 days) was considered. Thus, unusual precipitation and snowfall variations associated with a blocking event were evaluated in total amounts during a blocking period. For each blocking period, climate values and variations of precipitation and snowfall amounts were calculated (Table 2); climate values represent the average over the 57-year study period, and variations represent differences from the climate values.

\footnotetext{
${ }^{1}$ Kuwano-Yoshida (2014) actually used surface pressure to calculate the local deepening rate. However, we here use sea-level pressure since it is the same over the Pacific.

${ }^{2}$ We also examined the meridional eddy heat flux $v ' T$ ' at $850 \mathrm{hPa}$ (here prime indicates an 8-day high-pass filtered component), but almost the same results were obtained.
}

Table 2. Precipitation $[\mathrm{mm}]$ and snowfall $[\mathrm{cm}]$ amounts during the blocking periods ( 3 decades around the blocked days) in the Kanto and PNJ (Pacific Ocean side of northern Japan) areas. "Case \#" is as Table 1. The amounts are displayed as the "(variation)/(climate) value." The climate values represent the average for each blocking period over the 57-year study period, and variations represent departures from the calculated climate values. The amounts with positive variations are shown in bold type. The snowfall amounts before 1960 are denoted as "//" because snowfall data is not archived before that year. Note that the Kanto and PNJ areas are composed of the 8 points of Kohu, Yokohama, Tokyo, Maebashi, Utsunomiya, Kumagaya, Tsukuba and Chiba and the 8 points of Fukushima, Sendai, Morioka, Hachinohe, Uraga, Obihiro, Kushiro, and Nemuro, respectively (Fig. 1a). Note that since precipitation and snowfall variations on the Japan-Sea side of northern Japan (based on the data from 11 points of Kanazawa, Toyama, Niigata, Yamagata, Akita, Fukaura, Esashi, Otaru, Sapporo, Haboro, and Wakkanai) were positive in only 7 and 4 blocking cases (not shown), respectively, the influence of blocking on precipitation

\begin{tabular}{|c|c|c|c|c|}
\hline \multirow{2}{*}{ case \# } & \multicolumn{2}{|c|}{$\begin{array}{l}\text { Precipitation amount } \\
{[\mathrm{mm}]}\end{array}$} & \multicolumn{2}{|c|}{$\begin{array}{l}\text { Snowfall amount } \\
{[\mathrm{cm}]}\end{array}$} \\
\hline & Kanto & PNJ & Kanto & PNJ \\
\hline 195901 & $+59 / 39$ & $+39 / 50$ & // & // \\
\hline 196501 & $+4.2 / 39$ & $+23 / 50$ & $-0.64 / 3.6$ & $-7.7 / 39$ \\
\hline 196902 & $+66 / 53$ & $+46 / 45$ & $-1.6 / 9.2$ & $+29 / 43$ \\
\hline 197902 & $+27 / 53$ & $+58 / 45$ & $-4.8 / 9.2$ & $+16 / 43$ \\
\hline 198001 & $+19 / 39$ & $+0.06 / 50$ & $-0.14 / 3.6$ & $+5.4 / 39$ \\
\hline 198401 & $+2.2 / 41$ & $-18 / 47$ & $+36 / 5.5$ & $+10 / 42$ \\
\hline 198502 & $+95 / 51$ & $+23 / 40$ & $-4.6 / 8.1$ & $+19 / 36$ \\
\hline 199402 & $+38 / 60$ & $+16 / 43$ & $+16 / 6.7$ & $-8.9 / 33$ \\
\hline 199801 & $+63 / 41$ & $+15 / 47$ & $+37 / 5.5$ & $+26 / 42$ \\
\hline 200001 & $+11 / 41$ & $+35 / 47$ & $-5.4 / 5.5$ & $+16 / 42$ \\
\hline 200602 & $+26 / 60$ & $-1.6 / 43$ & $-6.6 / 6.7$ & $-10 / 33$ \\
\hline 201012 & $+72 / 42$ & $+\mathbf{1 1 7 / 5 7}$ & $-0.78 / 0.78$ & $+16 / 26$ \\
\hline 201201 & $+11 / 46$ & $-17 / 45$ & $-4.6 / 6.7$ & $-10 / 44$ \\
\hline 201402 & $+96 / 51$ & $+15 / 40$ & $+69 / 8.1$ & $+22 / 36$ \\
\hline
\end{tabular}
and snowfall in this area is unclear.

In the Kanto area, precipitation increases for all blocking cases; the most significant precipitation increase was approximately 2.9 times greater than the respective climate value (201402 case). In contrast, snowfall variations in the Kanto area showed positive only for four cases, all of which were significant increases; there was 3.4 to 9.5 times more snowfall than the climate values. In the PNJ area, precipitation and snowfall variations were positive in 11 and 9 blocking cases, respectively, which is greater than half the number of cases. Therefore, most of the blocking events increased precipitation and snowfall in the PNJ area.

Variations in climate during the blocking periods were examined from the frequency distribution of precipitation and snowfall amounts for each decade (Fig. 3). At first glance, although all climatological distributions except for snowfall distribution in the Kanto area resemble an exponential decay function, the decay for the blocking cases is weaker than that for all the winters. Because the weaker decay indicates a higher probability of events occurring in right-hand bins (e.g., Pelly and Hoskins 2003), the occurrence of an extreme precipitation/snowfall event is more easily influenced by blocking events. Though exponential decay is not apparent for snowfall in the Kanto area, 7 of the 12 most extreme snowfall decades occurred in the blocking periods (the numbers in Fig. 3b), which supports that blocking influences snowfall in the Kanto area.

In summary, during blocking events, precipitation was almost always increased in both the Kanto and PNJ areas, and most snowfall amounts were significantly increased in the PNJ area. Yet, the increase of snowfall in the Kanto area was not robust. This could be related to the mean temperature in each area; the average surface temperature over all blocking periods was $-1.6^{\circ} \mathrm{C}$ in the PNJ area and $4.8^{\circ} \mathrm{C}$ in the Kanto area. Thus, climatological conditions in the Kanto area make significant snowfall difficult, and large-scale factors other than the blocking would be required for snow to occur as it did in February 2014. 

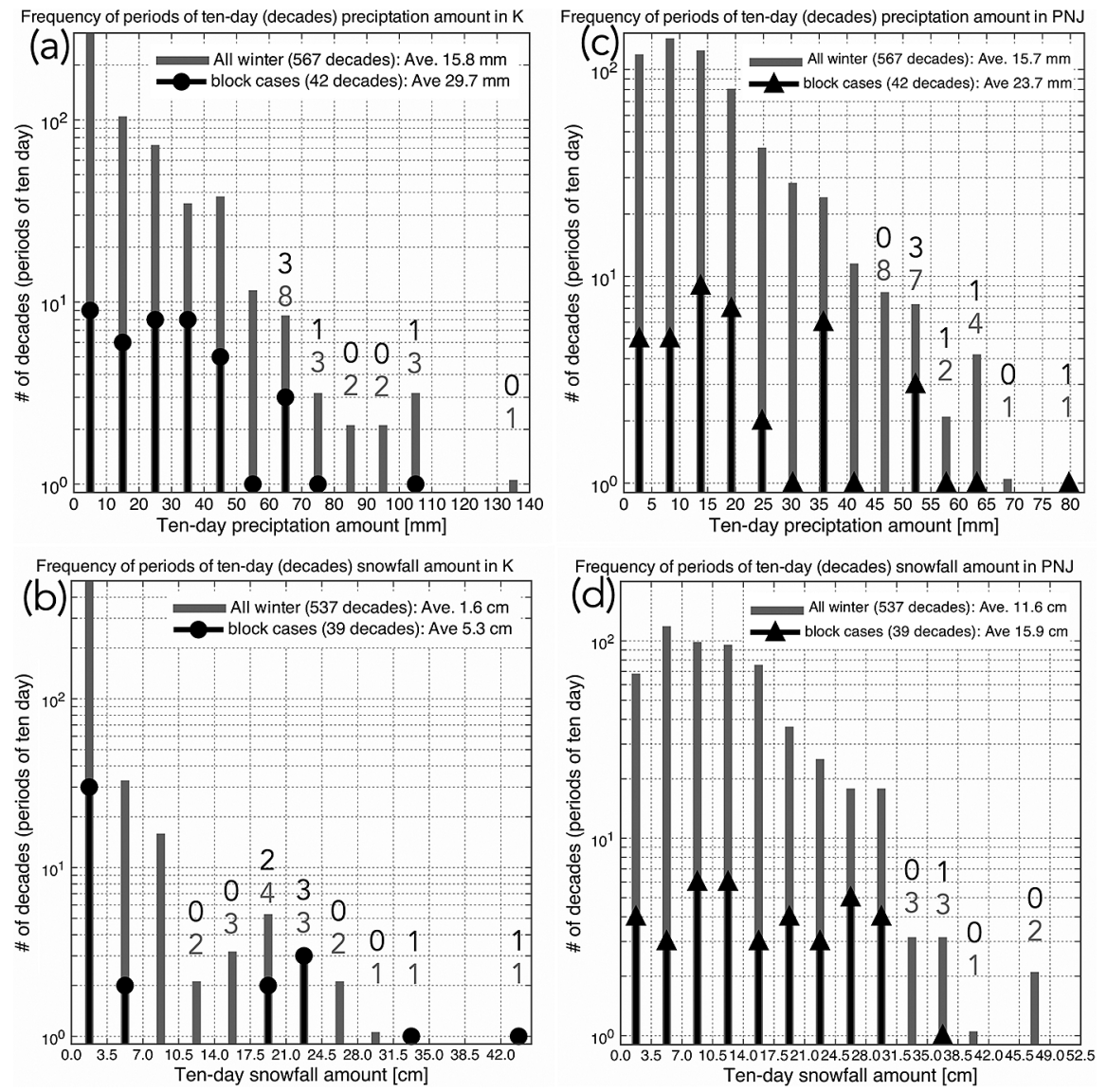

Fig. 3. Frequency distributions of the (a and c) precipitation and ( $b$ and d) snowfall amounts in each decade in the (a and b) Kanto and (c and d) PNJ areas during all the winters (grey) and blocking periods (black with marks). The vertical axis and horizontal bins indicate number of decades (periods of 10 days) and precipitation $[\mathrm{mm}] /$ snowfall $[\mathrm{cm}]$ amounts in a decade, respectively. Note that the numbers of decades are plotted on a log scale (to base 10). The decade numbers for extreme events less than 10 decades for a bin are denoted at the upper parts of the bins as grey for all the winters and black for the blocking periods.

\section{Cold air mass from the polar region}

Large-scale conditions conducive to snowfall in the Kanto area where the mean surface temperature is above $0^{\circ} \mathrm{C}$ were investigated by compositing the 4 blocking cases with positive snowfall variations in the Kanto area (snow-comp, the 4 cases of 198401, 199402, 199801, and 201402) and the other 10 blocking (nonsnow-comp) and comparing them. For snowfall in the Kanto area, coldness of temperature near the surface has especially been paid attention (Matsuo et al. 1981). Therefore, we focused on large-scale cold air inflow as a necessary condition for snowfall accompanied by cyclones. Because temperature distribution on the blocking time scale ( $\sim 10$ days) strongly reflects the influence of northward warm advection by blocking (Fig. 2b), the temperature field in the Kanto area does not become so cold. Therefore, we speculate that the large-scale cold-air inflows such as the repeated cold outbreaks from Eurasia Continent and the polar region were needed as another large-scale condition. Since it is under the influence of the winter East Asian monsoon, Japan is strongly affected by cold outbreaks.

Cold outbreaks are quantified by the cold air mass flux proposed by Iwasaki et al. (2014). The cold air mass is the sum of the mass below a threshold isentropic surface in the lower troposphere, which is the pressure difference between the ground surface and the isentropic surface. Thus, the flux quantifies the strength of cold air movements in the lower troposphere. An advantage to using this flux is that cold air movements can be clearly observed because the flux is derived from conservative laws. In fact, Shoji et al. (2014) showed the usefulness of flux for quantifying cold outbreak events in the East Asian region. For the analyses here, the threshold isentropic surface was defined as $280 \mathrm{~K}$ as it was in Shoji et al. (2014).

The distributions of the cold air mass flux for the winteraveraged climatology, the snow-comp, and the nonsnow-comp are shown in Figs. 4a, b, c. The climatological distribution in Fig. 4a reveals repeated cold outbreaks as a cold air stream southeastward from east Siberia to Japan. When examining the snow-comp distribution (Fig. 4b), the enhanced stream anomaly appears together with the western Pacific blocking over the Okhotsk Sea, implying that the stream was enhanced over northern China and increased the southward outbreaks over Japan. Similar to the snow-comp distribution, the nonsnow-comp distribution also shows the enhancement of the stream over northern China, but the blocking is located over east of the Kamchatka and the stream anomaly is directed northward at north of Japan along with the west side of the blocking anticyclone (Fig. 4c). As a result, the increased southward cold outbreaks did not appear over Japan. The different distributions of the stream anomalies between the snow-comp and nonsnow-comp cases imply that the streams near Japan are to some extent regulated by the blocking.

The results imply that the enhanced stream anomaly together with the blocking can have an influence on frequency of the southward cold air outbreaks over Japan. In fact, the 10 day averaged $-6^{\circ} \mathrm{C}$ line at $850 \mathrm{hPa}$ was slightly located south in the snow-comp relative to the nonsnow-comp and climatology (Figs. 4a, b, c). The southward cold outbreaks over Japan were dependent on the positions of the blocking. The blocking in the snow-comp situation was located northwestward relative to that in the nonsnow-comp. Nonetheless, the southward outbreaks appear to be small from a 
(a) mag_dpf \& dp-flux @280K (DJF clim)

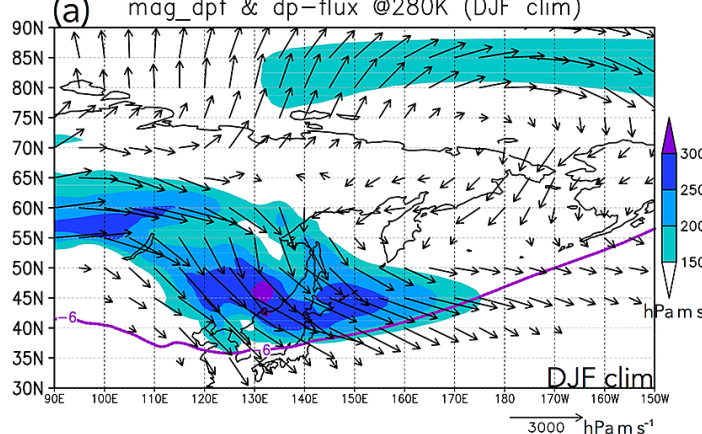

(b)

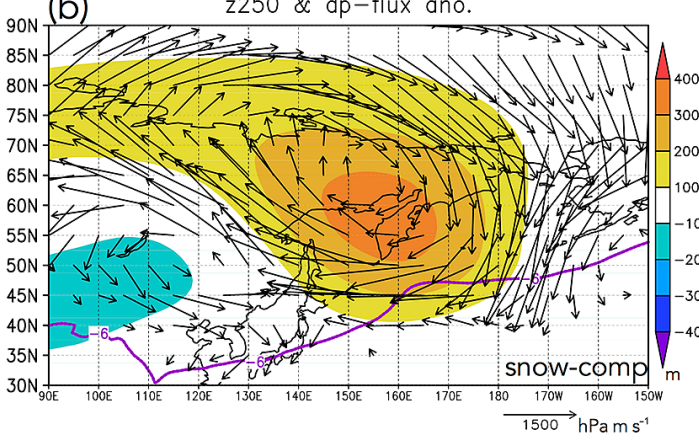

(c) $\quad 2250 \& \mathrm{dp}-$ flux ano.

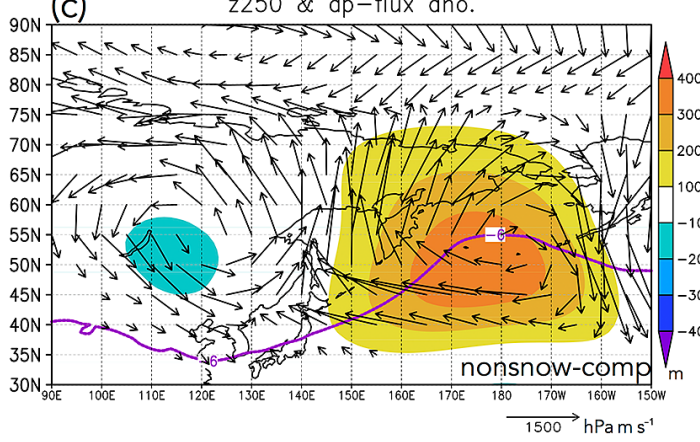

$\mathrm{vf}(@ 280)$ Snow-Nonsnow \& t-values

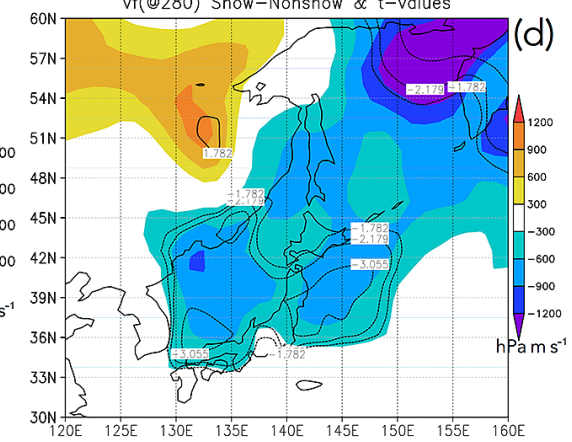

tmp(@850) Snow-Nonsnow \& t-values

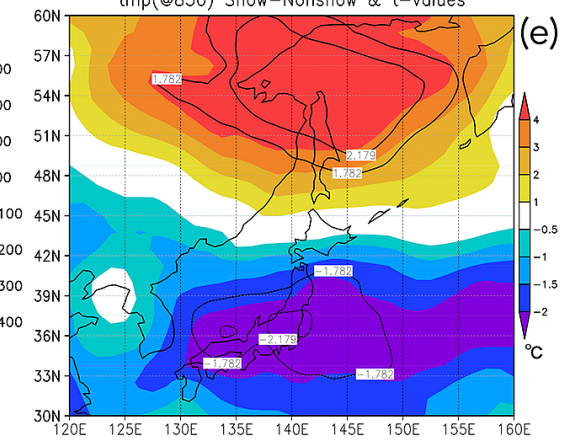

hgt $(@ 250)$ Snow-Nonsnow \& t-values

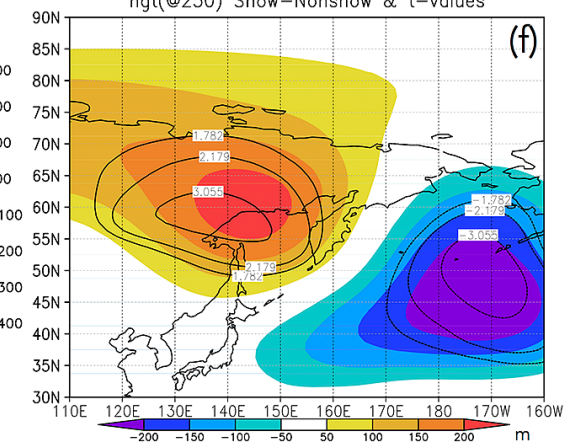

Fig. 4. $(\mathrm{a}-\mathrm{c})$ Averaged cold air mass flux $\left[\mathrm{hPa} \mathrm{m} \mathrm{s}{ }^{-1}\right]$ (vectors) for (a) the winter (December to February) climatology and the 10-day running mean anomalies at (b) the 4 blocked days with snowfall in the Kanto area (snow-comp) and (c) the other 10 blocked days (nonsnow-comp) from their climatology. Shades indicate (a) magnitude of the flux $\left[\mathrm{hPa} \mathrm{m} \mathrm{s}{ }^{-1}\right]$ and ( $\mathrm{b}$ and c) the geopotential height anomalies $[\mathrm{m}]$ at $250 \mathrm{hPa}$. Purple contours are the averaged $-6^{\circ} \mathrm{C}$ lines at $850 \mathrm{hPa}$. (d-f) The differences (shading) of 10-day running mean anomalies of (d) meridional cold air mass flux [hPa $\mathrm{m} \mathrm{s}^{-1}$ ] (the northward flux here is defined as positive), (e) temperature $\left[{ }^{\circ} \mathrm{C}\right]$ at $850 \mathrm{hPa}$, and (f) geopotential height [m] at $250 \mathrm{hPa}$ between the snow-comp and nonsnow-comp cases (snow-comp minus nonsnow-comp), respectively. The solid (dashed) contours indicate the $t$ values of $+(-) 1.782,+(-) 2.179$, and $+(-) 3.055$ that correspond to the 90,95 , and $99 \%$ confidence levels for a two-sided Student's $t$ test, respectively.

large-scale view relative to the position difference of the blocking.

We then checked the more enhanced outbreaks in the snowcomp cases than those in the nonsnow-comp. Figures $4 \mathrm{~d}$, e show the differences of the meridional cold air mass flux and $850-\mathrm{hPa}$ temperature, respectively, between the two cases (snow-comp minus nonsnow-comp). The results both reveal the colder condition in the snow-comp cases near the Kanto area by indicating that the southward cold inflow over Japan in the snow-comp cases was greater and the temperature in the lower troposphere was colder, although their differences were rather confined into small regions. As we found from Figs. 4b, c, blocking positions were clearly different between the snow-comp and nonsnow-comp cases (Fig. 4f). It should be noted that the storm-track distributions in the snowcomp and the nonsnow-comp were almost the same.

We conclude that, from a large-scale view, western Pacific blocking together with enhanced cold air streams from east Siberia can cause unusual snowfall in the Kanto area. However, this conclusion is only based on a large-scale perspective; therefore, blocking would be a necessary condition for the snowfall but not the only required condition.

\section{Concluding remarks}

For western Pacific blocking similar to that of February 2014, which could cause large precipitation/snowfall in the Kanto area and on the Pacific Ocean side of northern Japan (PNJ), their largescale features were investigated. The 14 strongest western Pacific blocking during the past 57 winters between December and February of 1958-2014 were selected by defining a blocking index, and their large-scale composited fields were analyzed. Through the analysis, it was found that the blocking flow shifts the cyclone (storm) track from the usual (climatological) eastward path along the mid Pacific to a northeastward path along the east coast of Japan. Local observation data also indicated that when the blocking occurred, precipitation amounts in the Kanto area and snowfall in the PNJ increased. These results revealed that the shift of the storm track increased precipitation/snowfall in these areas.

In addition, another large-scale condition apart from blocking was required for snowfall events to occur in the Kanto area. As the large-scale condition, a strong southward inflow of cold air to Japan existed in the lower troposphere in blocking cases with 


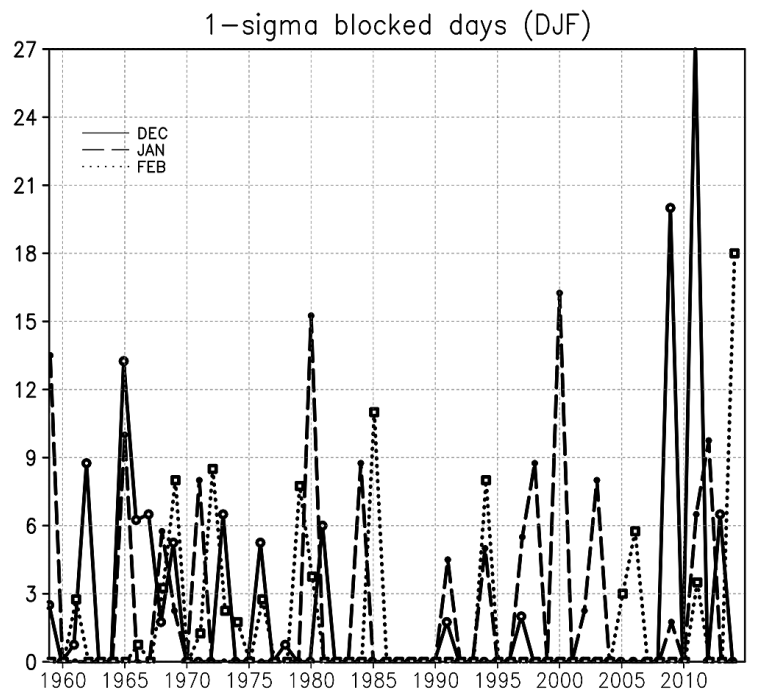

Fig. 5. Interannual variation of the blocking frequency in December (solid), January (dashed), and February (dotted) during 1958-2014. Vertical and horizontal axes indicate blocking frequency [days] and years, respectively. The frequency is the number of days during a month when the index $I_{D}$ was less than 1-standard deviation from the climatology.

snowfall in the Kanto area. For the inflow, an enhanced cold air stream from east Siberia carried cold polar air to Japan when the blocking occurred over the Okhotsk Sea.

Lastly, we would like to introduce two speculations: one is on the predictability of extreme snowfall events in the Kanto area and the other is on the interannual variability of western Pacific blocking.

In regards to predictability, it may be important to connect the different predictability time scales between blocking and precipitation types. The time scale of forecasting block maintenance is $\sim 1$ week or more (e.g., Matsueda 2011), while that for precipitation types is less than few days (Hara 2013). Our results show that the position of blocking could suggest the precipitation type.

For interannual variability, Fig. 5 shows interannual variations of western Pacific blocking frequency, which were quantified by using the blocking index defined in this study. The figure indicates that there are some oscillations rather than a trend, which is consistent with Barnes et al. (2014) who investigated interannual blocking variabilities in the Northern Hemisphere. Note that the mechanism of these variabilities has not been fully discussed. In addition, the figure shows the large blocking frequency in recent years. This, in turn, implies that large-scale atmospheric fields may trigger extreme events in the near future related to western Pacific blocking as those during the snowfall events in February 2014.

\section{Acknowledgements}

This research was supported by the Grants-in-Aids for Scientific Research (KAKENHI) numbers 25900003, 25800267, and 24540470. The code for cold air mass flux calculations was kindly provided by Yuki Kanno and Toshiki Iwasaki at Tohoku University. We would like to thank Fumichika Uno, Kenichi Ueno, Sento Nakai, and two anonymous reviewers for their helpful comments that substantially improved the quality of this manuscript. The local observation data was obtained from the archives of the Japan Meteorological Agency. Figures were drawn using GrADS and MjoGraph.

\section{Supplement}

Supplementary materials include 4 figures.

\section{References}

Barnes, E. A., E. Dunn-Sigouin, G. Masato, and T. Woollings, 2014: Exploring recent trends in Northern Hemisphere blocking. Geophys. Res. Lett., 41, 638-644.

Green, J. S. A., 1977: The weather during July 1976: Some dynamical considerations of the drought. Weather, 32, 120126.

Hara, T., 2013: A heavy snowfall event on 14 Feb. 2013. Textbooks for the training course about numerical weather prediction, 46, 71-89. (in Japanese) http://www.jma.go.jp/ jma/kishou/books/nwptext/46/chapter4.pdf.

Iwasaki, T., T. Shoji, Y. Kanno, M. Sawada, M. Ujiie, and K. Takaya, 2014: Isentropic analysis of polar cold airmass streams in the northern hemispheric winter. J. Atmos. Sci., 71, 2230-2243.

Kobayashi, S., Y. Ota, Y. Harada, A. Ebita, M. Moriya, H. Onoda, K. Onogi, H. Kamahori, C. Kobayashi, H. Endo, K. Miyaoka, and K. Takahashi, 2015: The JRA-55 reanalysis: General specifications and basic characteristics. J. Meteor. Soc. Japan, 93, 5-48.

Kuwano-Yoshida, A., 2014: Using the local deepening rate to indicate extratropical cyclone activity. SOLA, 10, 199-203.

Matsueda, M., 2011: Predictability of Euro-Russian blocking in summer of 2010. Geophys. Res. Lett., 38, L06801, doi: 10.1029/2010GL046557.

Matsuo, T., Y. Sasyo, and Y. Sato, 1981: Relationship between types of precipitation on the ground and surface meteorological elements. J. Meteor. Soc. Japan, 59, 462-476.

Pelly, J. L., and B. J. Hoskins, 2003: A new perspective on blocking. J. Atmos. Sci., 60, 743-755.

Shoji, T., Y. Kanno, T. Iwasaki, and K. Takaya, 2014: An isentropic analysis of the temporal evolution of East Asian cold air outbreaks. J. Climate, 27, 9337-9348.

Ueno, K., 1993: Inter-annual variability of surface cyclone tracks, atmospheric circulation patterns, and precipitation patterns, in winter. J. Meteor. Soc. Japan, 71, 655-671.

Yamazaki, A., and H. Itoh, 2013: Vortex-vortex interactions for the maintenance of blocking. Part I: The selective absorption mechanism and a case study. J. Atmos. Sci., 70, 725-742.

Manuscript received 29 November 2014, accepted 31 March 2015 SOLA: https://www.jstage.jst.go.jp/browse/solal 